\title{
PENERAPAN METODE RESITASI DAN DRILL DALAM MENINGKATKAN AKTIVITAS PEMBELAJARAN PSIKOLOGI PENDIDIKAN PADA MAHASISWA PENDIDIKAN EKONOMI UNIVERSITAS PAMULANG
}

\author{
METHA LUBIS \\ Dosen Program Studi Pendidikan Ekonomi Universitas Pamulang \\ *) email: dosen02252@unpam.ac.id
}

\begin{abstract}
ABSTRAK
Tujuan penelitian ini adalah untuk meningkatkan aktivitas belajar mahasiswa kelas 05PIEM001 Pendidikan Ekonomi, FKIP, Universitas Pamulang pada pembelajaran Psikologi Pendidikan melalui metode Resitasi dan Drill. Pendekatan penelitian yang digunakan adalah mix method, dengan metodologi Penelitian Tindakan Kelas. Adapun desain PTK yang digunakan adalah Kurt Lewin yang terdiri 3 siklus. Subjek penelitian adalah mahasiswa kelas 05PIEM001 Pendidikan Ekonomi, FKIP, Universitas Pamulang. Instrumen penelitian yaitu lembar observasi aktivitas mahasiswa, dan soal tes untuk mengetahui ketuntasan belajar mahasiswa pada pembelajaran Psikologi Pendidikan. Teknik analisis data menggunakan statistika deskriptif. Hasil penelitian menunjukkan bahwa siklus I, jumlah mahasiswa yang aktif mencapai 47\% dan persentase ketuntasan hasil belajar mencapai 59\%. Pada siklus II jumlah mahasiswa yang aktif meningkat menjadi $60 \%$ dan persentase ketuntasan hasil belajar meningkat menjadi 77\%. Pada siklus III yang sekaligus menjadi hasil dalam penelitian ini, jumlah mahasiswa yang aktif meningkat menjadi $74 \%$ dan presentasi ketuntasan hasil belajar mahasiswa ikut meningkat menjadi $91 \%$. Simpulan penelitian adalah metode Resitasi dan Drill mampu meningkatkan aktivitas belajar mahasiswa pada pembelajaran Psikologi Pendidikan kelas 05PIEM001 Pendidikan Ekonomi, FKIP, Universitas Pamulang tahun ajaran $2018 / 2019$.
\end{abstract}

Kata Kunci: Metode Drill, Metode Resitasi, Aktivitas Belajar, Psikologi Pendidikan 


\section{PENDAHULUAN}

Psikologi Pendidikan merupakan salah satu matakuliah yang terdapat dalam kurikulum Pendidikan Ekonomi pada Fakultas Keguruan dan Ilmu Pendidikan di Universitas Pamulang. Matakuliah Psikologi Pendidikan memberikan bekal pengetahuan dan keterampilan dalam ruang lingkup Pendidikan yang berkenaan dengan masalah-masalah pada proses belajar dan mengajar.

Pengetahuan tentang psikologi sangat penting bagi dunia Pendidikan. Pengetahuan tentang psikologi sangat diperlukan dalam memahami karakteristik kognitif, afektif, dan psikomotorik peserta didik secara integral oleh pihak guru atau instruktur sebagai pendidik, pengajar, pelatih, pembimbing, dan pengasuh (Dodi, 2016; 60). Peserta didik memiliki karakteristik yang berbeda antara peserta didik yang satu dengan peserta didik lainnya, seperti : perilaku, kepribadian, sikap, minat, motivasi, perhatian, persepsi, daya pikir, inteligensi, fantasi, dan berbagai aspek psikologis lainnya. Karakteristik psikologis peserta didik yang berbeda harus diketahui dan dipahami oleh setiap guru yang berperan sebagai pendidik dan pengajar dikelas, agar proses pembelajarannya berhasil.

Aspek psikologis peserta didik harus dipahami oleh pihak guru di institusi Pendidikan, ini sangat berarti dalam membelajarkan peserta didik yang sesuai dengan sikap, minat, motivasi, aspirasi, dan kebutuhan peserta didik, sehingga pembelajaran di kelas dapat berlangsung secara optimal dan maksimal. Oleh karena itu, calon guru (mahasiswa) harus mempelajari Psikologi Pendidikan, agar nantinya menjadi guru yangseutuhnya. Namun kenyataannya, pembelajaran Psikologi Pendidikan belum sesuai yang diharapkan, masih banyak kekurangan. Permasalahan yang di temukan pada matakuliah Psikologi Pendidikan yaitu: mahasiswa belum aktif saat pembelajaran dan ketuntasan hasil belajar rendah. Hal ini dibuktikan dengan nilai mahasiswa pada ulangan tengah semester ganjil 2018/2019 yang belum maksimal. Kriteria ketuntasan minimal (KKM) yang ditentukan yaitu 70. Hasil evaluasi dari 22 mahasiswa terdapat sebanyak 9 mahasiswa tuntas KKM (41\%), dan mahasiswa tidak tuntas KKM sebanyak 13 mahasiswa 
(59\%). Rendahnya hasil belajar pada mahasiswa Pendidikan Ekonomi kelas 05PIEM001 menunjukkan bahwa kualitas pembelajaran Psikologi Pendidikan masih rendah.

Berdasarkan hasil observasi dan refleksi yang telah dilakukan, maka permasalahan timbul disebabkan oleh beberapa faktor, dan salah satu faktor penyebabnya adalah metode mengajar dosen. Dosen mengajar menggunakan metode ceramah satu arah dan mahasiswa hanya mencatat serta mendengarkan. Dosen saat mengajar kurang berinteraksi dengan mahasiswa, sehingga pembelajaran hanya berfokus pada dosen. Dosen belum menerapkan metode-metode dalam pembelajaran yang dapat meningkatkan keaktifan mahasiswa pada mata kuliah Psikologi Pendidikan. Masalah yang berkaitan dengan aktivitas mahasiswa kelas 05PIEM001 menunjukkan bahwa mahasiswa tidak berpartisipasi aktif dalam pembelajaran Psikologi sehingga ketuntasan hasil belajar rendah.

Permasalahan yang ditemukan pada kelas 05PIEM001 yaitu: rendahnya aktivitas mahasiswa dalam matakuliah Psikologi Pendidikan pada Program Studi Pendidikan Ekonomi Universitas
Pamulang. Aktivitas pembelajaran harus ditingkatkan, maka salah satu cara yang dapat dilakukan adalah dengan penerapan metode Resitasi dan Drill. Penerapan metode pembelajaran ini diharapkan meningkatkan aktivitas mahasiswa kelas 05PIEM001 dalam pembelajaran Psikologi Pendidikan. Dengan kata lain, upaya dalam meningkatkan aktivitas mahasiswa akan berdampak positif terhadap peningkatan prestasi belajar atau ketuntasan hasil belajar mahasiswa.

Berdasarkan uraian di atas maka akan dikaji penelitian tindakan kelas yang berjudul: Penerapan Metode Resitasi Dan Drill dalam Meningkatkan Aktivitas mahasiswa pada Pembelajaran Psikologi Pendidikan di Pendidikan Ekonomi Universitas Pamulang. Adapun rumusan masalah sebagai berikut: Bagaimana cara meningkatkan aktivitas pembelajaran Psikologi Pendidikan pada mahasiswa Pendidikan Ekonomi kelas 05PIEM001 Universitas Pamulang?. Rincian dari rumusan masalah tersebut adalah sebagai berikut: Bagaimana penerapan metode resitasi dan drill untuk meningkatkan aktivitas mahasiswa? Bagaimana penerapan metode resitasi dan drill dalam 
meningkatkan ketuntasan hasil belajar mahasiswa?.

\section{KAJIAN TEORI}

Pembelajaran psikologi sangat diperlukan oleh pihak guru atau instruktur sebagai pendidik, pengajar, pelatih, pembimbing, dan pengasuh dalam memahami karakteristik kognitif, afektif, dan psikomotorik peserta didik secara integral (Dodi, 2016; 60). Psikologi Pendidikan merupakan ilmu yang mempelajari bagaimana manusia itu belajar dan berkembang ( Dodi, $2016: 59)$.

Psikologi Pendidikan adalah sebuah displin psikologi yang khusus mempelajari, meneliti dan membahas seluruh tingkah laku individu yang terlibat dalam Pendidikan yang meliputi tingkah laku belajar, tingkah laku mengajar dan tingkah laku belajar mengajar (Syah, 2010: 24).

Tingkah laku belajar,mengajar dan belajar-mengajar dapat dilihat dari aktivitas belajar. Aktivitas belajar mahasiswa yang tidak baik akan berpengaruh pada penurunan hasil belajar atau ketuntasan belajar (Aunurrahman, 2012: 185). Dalam meningkatkan aktivitas belajar mahasiswa maka pembelajaran psikologi dilaksanakan dengan menggunakan metode pembelajaran, diantaranya adalah metode Resitasi dan Drill.

Metode Resitasi merupakan pemberian tugas kepada mahasiswa diluar jadwal matakuliah Psikologi Pendidikan dipertanggungjawabkan kepada dosen yang bersangkutan (Aditya: 2016: 167). Metode Resitasi dapat digunakan untuk berbagi materi yang terkait erat dengan aspek knowledge, afektif dan psikomotor. Materi- materi yang ada pada pembelajaran Psikologi Pendidikan bisa diajarkan dengan metode Resitasi.

Pengajaran metode Resitasi tidak dilaksanakan dirumah saja, melainkan dapat dikerjakan di perpustakaan, dilaboratorium, atau ditempat lainnya yang berhubungan dengan pelajaran yang diberikan (Aditya, 2016: 168). Resitasi memiliki pengertian yang luas dibandingkan homework, namun keduanya memiliki kesamaan yaitu: unsur tugas, dikerjakan peserta didik dan hasilnya dilaporkan kepada pendidik. Pemberian tugas dilakukan untuk menyelesaikan pembelajaran yang telah ditetapkan. Pemberian tugas juga bertujuan untuk mengisi waktu 
luang peserta didik agar tidak banyak bermain.

Metode drill merupakan cara membelajarkan peserta didik agar dapat mengembangkan kemahiran dan atau keterampilan atas apa yang dipelajari mahasiswa serta dapat mengembangkan sikap dan kebiasaan (Majid; 2013: 214). Metode drill adalah suatu teknik yang digunakan sebagai suatu cara mengajar dimana mahasiswa melaksanakan kegiatan- kegiatan latihan, sehingga mahasiswa dapat memiliki kecakapan atau keterampilan yang lebih tinggi dari apa yang telah dipelajarinya (Rimba and Hidayat, 2016).

Metode drill ini digunakan untuk tujuan mengembangkan kecakapan intelektual mahasiswa pada matakuliah Psikologi Pendidikan. Metode drill ini diterapkan kepada mahasiswa seperti: pemberian penjelasan konsep, prinsip, dan pelaksanaan latihan terhadap topik yang sudah dipelajari, serta pemberian bimbingan selama latihan. Penerapan metode drill sebagai suatu upaya dalam meningkatkan kemahiran mahasiswa dalam berkomunikasi pada Psikologi Pendidikan.

Penelitian yang relevan dengan penelitian ini yaitu: Watt, Charles,
Brandon, Grant, Andrew, and Kathleen (2014) menunjukkan bahwa dengan metode Resitasi dapat meningkatkan keberhasilan. Mayer, Jeremy, and Marion (2017) menunjukkan bahwa metode Resitasi dapat meningkatkan keterlibatan mahasiswa dalam pembelajaran. Wenno, Pieter, and Luky (2016) menunjukkan bahwa dengan metode drill dapat meningkatkan prestasi belajar sains siswa menjadi lebih baik. Kusumawati dan Randi (2016) menyatakan bahwa dengan metode drill terjadi peningkatakan kualifikasi kemampuan siswa dalam pemecahan masalah.

\section{METODE PENELITIAN}

Penelitian ini menggunakan pendekatan mix method, dengan metodologi penelitian tindakkan kelas. Desain PTK yang digunakan adalah Kurt Lewin sebanyak 3 siklus dengan masing-masing siklus 4 tahap, yaitu: (1) tahap perencanaan; (2) tahap pelaksanaan; (3) tahap pengamatan; dan (4) tahap refleksi.

Subjek pada penelitian ini adalah mahaiswa pada matakuliah Psikologi Pendidikan kelas 05PIEM001 
Pendidikan Ekonomi, FKIP, Universitas Pamulang sebanyak 22 mahasiswa.

Teknik dan instrument pengumpulan data pada penelitian ini disajikan pada Tabel 1.

\section{Tabel 1. Teknik dan Instrumen}

\begin{tabular}{|l|l|l|}
\hline Jenis data & Teknik & Instrumen \\
\hline $\begin{array}{l}\text { Aktivitas } \\
\text { mahasiswa }\end{array}$ & Observasi & $\begin{array}{l}\text { Lembar } \\
\text { Observasi } \\
\text { aktivitas } \\
\text { mahasiswa }\end{array}$ \\
\hline $\begin{array}{l}\text { Ketuntasan } \\
\text { hasil } \\
\text { belajar } \\
\text { mahasiswa }\end{array}$ & Tes & Soal tes \\
\hline
\end{tabular}

Analisis data menggunakan statistik deskriptif yang terdiri dari penyajian data, mean, persentil, dan range. Statistika deskriptif pada penelitian ini hanya menerangkan kelompok hasil data tanpa mengeneralisasikan.

\section{HASIL DAN PEMBAHASAN}

Aktivitas dan ketuntasan hasil belajar mahasiswa pada matakuliah Psikologi Pendidikan pada siklus I, II, dan III terus mengalami peningkatan. Peningkatan aktivitas dan ketuntasan hasil belajar mahasiswa Pendidikan Ekonomi pada perkuliahan Psikologi Pendidikan dengan metode Resitasi dan Drill akan gambarkan.

\section{Aktivitas Mahasiswa}

Aktivitas mahasiswa pada penelitian ini merupakan segala kegiatan yang dilakukan didalam proses pembelajaran (interaksi mahasiswa dan dosen), yang ditekankan pada keaktifan fisik, mental, inteltual, dan emosional dalam memperoleh hasil belajar yang maksimal diperkuliahan Psikologi Pendidikan dengan metode Resitasi dan Drill. Peningkatan jumlah mahasiswa yang aktif pada setiap siklus ditunjukan pada Gambar 1.

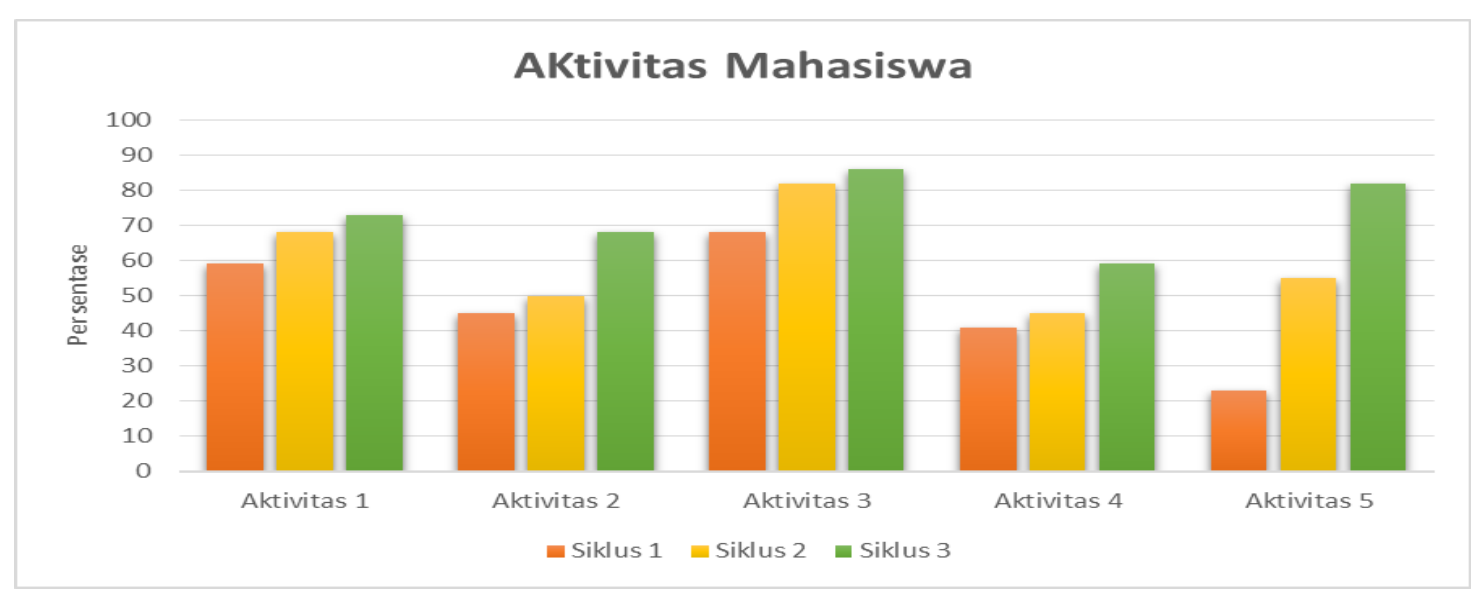




\section{Gambar 1. Persentase Jumlah Mahasiswa Aktif}

Keterangan :

Aktivitas 1 : Kesiapan menerima pembelajaran

Aktivitas 2 : Melaksanakan perintah dosen, bertanya dan menanggapi

Aktivitas 3 : Memperhatikan penjelasan dosen

Aktivitas 4 : Kemampuan mengerjakan tugas dari dosen

Aktivitas 5 : Kemampuan melaksanakan keaktifan dari hasil latihan

Dari Gambar 2, hasil observasi aktivitas mahasiswa pada perkuliahan Psikologi Pendidikan dengan metode Resitasi dan Drill pada siklus I, II, dan III mengalami peningkatan. Persentase jumlah mahasiswa yang aktif pada siklus I sebesar 47\%, pada siklus II sebesar $60 \%$ dan pada siklus III sebesar $74 \%$.

\section{Ketuntasan Hasil Belajar Mahasiswa Pada Pembelajaran Psikologi Pendidikan}

Hasil penelitian menunjukkan bahwa terdapat peningkatan jumlah mahasiswa yang tuntas dalam pembelajaran Psikologi Pendidikan dengan menggunakan metode Resitasi dan Drill dari siklus I, II, dan III. Hal ini dibuktikan dengan semakin tingginya persentase jumlah mahasiswa yang tuntas dalam pembelajaran Psikologi Pendidikan, seperti berikut : siklus 1 sebesar 59\%, siklus II sebesar 77\% dan siklus III sebesar $91 \%$.
Berdasarkan data tersebut, dapat disimpulkan bahwa ketuntasan hasil belajar mahasiswa kelas 05PIEM001 sudah semakin meningkat yang ditunjukkan pada Gambar 2.

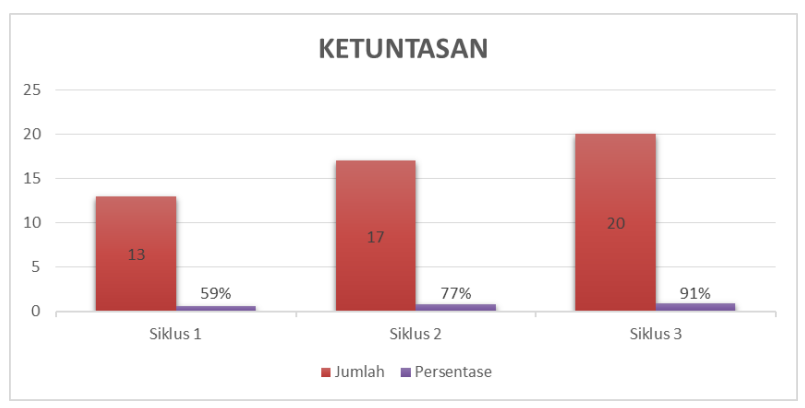

Gambar 2. Ketuntasan Hasil Belajar Mahasiswa

Penelitian sebelumya oleh Toklucu and Tay (2016) menunjukkan bahwa metode pembelajaran dapat meningkatkan prestasi belajar siswa. Mayer, Jeremy, and Marion (2017) menunjukkan bahwa metode Resitasi dapat meningkatkan aktivitas dan/atau keterlibatan mahasiswa dalam pembelajaran. Wenno, Pieter, and Luky (2016) menunjukkan bahwa dengan 
metode drill meningkatkan prestasi belajar sains siswa menjadi lebih baik.

Penelitian ini membuktikan bahwa metode Resitasi dan Drill dapat membantu meningkatkan aktivitas dan ketuntasan hasil belajar mahasiswa pada perkuliahan Psikologi Pendidikan.

Berdasarkan penelitian yang telah dilakukan, terlihat bahwa terjadi peningkatan jumlah mahasiswa yang aktif dan mahasiswa yang tuntas dalam belajar pada matakuliah Psikologi Pendidikan di kelas 05PIEM001 Pendidikan Ekonomi, FKIP, Universitas Pamulang. Hal ini dikarenakan metode Resitasi dan Drill adalah metode yang menuntut mahasiswa untuk selalu berlatih dan berlatih dalam memahami dan menguasai materi pembelajaran pada perkuliahan Psikologi Pendidikan. Mahasiswa mengerjakan tugas yang diberikan baik dikerjakan dikampus, perpustakaan maupun dilingkungan masyarakat, dengan syarat dapat menemukan jawaban atas pertanyaan yang diberikan. Sehingga, hal ini dapat meningkatkan pengayaan wawasan mahasiswa mengenai materi yang diberikan dalam perkuliahan dan juga memberikan makna terhadap apa yang telah dipelajarinya.

\section{SIMPULAN DAN SARAN}

Berdasarkan analisis data dan pembahasan hasil penelitian dapat disimpulkan bahwa penerapan metode Resitasi dan Drill dapat memperbaiki keaktifan mahasiswa pada matakuliah Psikologi Pendidikan di kelas 05PIEM001 Program studi Pendidikan Ekonomi, FKIP, Universitas Pamulang dengan menggunakan indikator yaitu meningkatnya aktivitas dan ketuntasan hasil belajar mahasiswa.

Saran diberikan berdasarkan hasil penelitian, sebagai berikut: sebaiknya dalam proses pembelajaran dosen menggunakan metode pembelajaran yang tepat untuk meningkatkan aktivitas mahasiswa yang akan berdampak terhadap peningkatan ketuntasan hasil belajar mahasiswa tersebut.

\section{DAFTAR PUSTAKA}

Aditya, Dedy Yusuf. 2016. Pengaruh Penerapan Metode Pembelajaran Resitasi terhadap Hasil Belajar Matematika Siswa. Jurnal SAP Volume 1 No. 2, ISSN 2527967X.

Aunurrahman. 2012. Belajar dan Pembelajaran. Bandung: Alfabeta.

Dodi, Nofri. 2016. Pentingnya Guru Mempelajari Psikologi Pendidikan. Jurnal ilmu 
pengetahuan sosial, ISSN 2541$657 X$.

Kusumawati, Elli dan Randi Ahmad Irwanto. 2016. Penerapan Metode Pembelajaran Drill untuk Meningkatkan Kemampuan Pemecahan Masalah Matematis Siswa Kelas VIII SMP. Jurnal Pendidikan Matematika, Volume 4, Nomor 1, hal. 49-57.

Majid, A. 2013. Strategi Pembelajaran. Bandung, Indonesia: PT. Remaja Rosdakarya.

Mayer, Greg., Jeremy Lingle., and Marion, Usselman. 2017. Experience of Advanced High School Students in Synchronous Online Recitations. Educational Technology \& Sociaty, 20(2), 1526.

Rimba, D., \& Hidayat, D. (2016). A Comparison of STAD and Drill Strategy in Increasing Grade $V$ Students Cognitive Achievement on Ratios. Polyglot: Jurnal Ilmiah, 12(1), 10-19.

Syah, Muhibin. 2010. Psikologi Pendidikan. Bandung: Remaja Rosdakarya.

Toklucu, S. Korkmaz., \& Tay, B. 2016. The Effect of Cooperative Learning Method and Systematic Teaching on Students Achievement and Retention of Knowledge in Social Study Lesson. Eurasian Journal of Educational Research, 66, 316334.
Watt, Jeffrey X., Charles R. Feldhaus., Brandon H. Sorge., Grant A. Fore., Andrew D. Gavrin., and Kathleen A. Marrs. 2014. The Effects of Implementing Recitation Activities on Success Rates in a College Calculus Course. Journal of the Scholarship of Teaching and Learning, Vol. 14, No. 4, pp. 1-17.

Wenno, Izaak Hendrik., Pieter Wattimena., and Lucky Maspaitela. 2016. Comparative study between Drill Skill and Concept attainment Model towards Physycs Learning Achievement. International Journal of Evaluation and Research in Education (IJERE), Vol. 5, No. 3, pp. 211-215. 